\title{
The effect of hydro-alcoholic Ferulago angulata extract on locomotor activity and anxiety caused by hypoperfusion ischemia in adult male rats
}

\author{
Shahrbanoo Alami-Rostami ${ }^{*}$, Maryam Rafieirad ${ }^{2}$ \\ ${ }^{1}$ Department of Biology, Islamic Azad University, Gomishan Center, Gorgan Branch, Gorgan, Iran \\ ${ }^{2}$ Department of Biology, Faculty of Sciences, Izeh Branch, Islamic Azad University, Izeh, Iran
}

\section{A R T I C L E I N F O}

Article Type:

Original Article

\section{Article History:}

Received: 18 July 2017

Accepted: 2 December 2017

\section{Keywords:}

Ferulago angulata

Ischemia

Locomotor activity

Anxiety

Rat

\begin{abstract}
A B S T R A C T
Introduction: Ischemia in rat brain causes severe neuronal damage and causes anxiety disorders. Ferulago angulata extracts contain phenolic compounds with powerful antioxidant activity. Therefore, the aim of this study was to evaluate the protective effect of F. angulata (Chevilan) extract on locomotor activity and anxiety in ischemia model in rats.

Methods: In this experimental study, 50 male Wistar rats weighing 200 to 250 g were randomly divided into 5 groups including intact (control), ischemic hypoperfusion without extract and three groups of ischemic hypo-perfusion, for 14 days, received 100, 200 and $400 \mathrm{mg} / \mathrm{kg}$ Chevilan extracts by gavage method daily. For ischemia common bilateral carotid arteries were isolated, blocked in two parts and cut from the middle section. Locomotor activity and anxiety were evaluated during an open field testing.

Results: The ischemic group showed a significant increase in anxiety and decrease in motor activity in the open field test. Administration of 100,200 or $400 \mathrm{mg} / \mathrm{kg}$ doses of the extract significantly reduced the number of raising hands, especially at the dose of $200(P<0.05)$, and all three doses reduced the number of defecations $(P<0.001)$. Consumption of $400 \mathrm{mg} / \mathrm{kg}$ dose of the F. angulata extracts showed a significant increase in the number of movements in the central house in the open field and between houses margins $(P<0.05)$.

Conclusion: Ferulago angulata extract reduces anxiety in animal models of ischemia, which is probably due to some phenolic compounds and its antioxidant activity.
\end{abstract}

Implication for health policy/practice/research/medical education:

Ferulago angulata extract reduces anxiety in animal models of ischemia, which is probably due to some phenolic compounds and its antioxidant activity and might be beneficial in these patients.

Please cite this paper as: Alami-Rostami S, Rafieirad M. The effect of hydro-alcoholic Ferulago angulata extract on locomotor activity and anxiety caused by hypoperfusion ischemia in adult male rats. J Herbmed Pharmacol. 2018;7(1):51-55. doi: 10.15171/ jhp.2018.09.

\section{Introduction}

Stress is a factor that by affecting living organisms, leads to reactions causing compliance and adjustment in the body's internal environment (1). However, when stress is prolonged or repetitive, it can be very harmful (2). The most common cause of ischemic stroke is the lack of adequate blood flow to the brain tissue and cut off blood flow to any part of the brain can lead to irreversible nerve damage (3). Hypoxia in the ischemic areas of the brain causes difficulties in mitochondrial function and also causes free radical damage (4), decreasing the activity and capacity of antioxidant enzymes. Increased free radicals lead to a serious damage to cellular components such as lipids, proteins and nucleic acids and eventually causes cell death (2). As time passes, the ischemia causes various complications such as learning and memory disorders, some types of pain, anxiety, fear, reproductive disorders and depression (2). Reducing the ischemia complications using herbal anti-ischemia and anti-oxidant active ingredients is of great clinical importance (5). Ferulago angulata with the name of Chevilan in Persian belongs to the family of Apiaceae (Umbelliferae) that is an extended 
family consisted of 300 genera and 3000 aromatic plants species (6). The Ferulago angulata extract has phenolic compounds and antioxidant properties and is known as an important medicinal plant of Iran (6-8). Due to their antioxidant activities, phenolic compounds are able to control free radicals. For this reason, they can be effective in preventing many diseases such as cancer, cardiovascular disease and neurological diseases and play an important role in human health (8). Therefore, in this study, the effect of $F$. angulata extract has been evaluated in the animal model of cerebral hypo-perfusion ischemia through investigating its effect on anxiety and movement activities.

\section{Materials and Methods}

Animals

The present study was carried out using adult male Wistar rats purchased from the proliferation and maintenance center of animals' house in Ahvaz Medical Science University with a weight range of 200 to $250 \mathrm{~g}$. Animals were kept in standard conditions of $20 \pm 2^{\circ} \mathrm{C}$ and 12hour photoperiodic cycle (light started from $7 \mathrm{am}$ ) and adequate access to intensive food from Tehran Pars Animal Companies and Chavdaneh of Shahreza in Isfahan and purified piped water in Izeh in the animal care center of Islamic Azad University of Izeh, inside standard cages in groups of four. To facilitate the process and for more compatibility with the environment and experimenter, animals were trained daily for a few minutes before the experiment (Ethical No. 1739608130014)

In this study, 50 male Wistar rats weighing 200 to $250 \mathrm{~g}$ were divided randomly into 5 equal groups as follows:

1. The control group without inducing ischemia and without receiving medication (control)

2. Ischemic hypo-perfusion group without receiving medication (ischemia)

3. Ischemic hypo-perfusion group, receiving a daily dose of $100 \mathrm{mg} / \mathrm{kg}$ of $F$. angulata extract for 14 days through gavage method (ischemia + F.A E100 mg/kg)

4. Ischemic hypo-perfusion group, receiving a daily dose of $200 \mathrm{mg} / \mathrm{kg}$ of $F$. angulata extract for 14 days through gavage method (ischemia + F.A E $200 \mathrm{mg} / \mathrm{kg}$ )

5. Ischemic hypoperfusion group, receiving a daily dose of $400 \mathrm{mg} / \mathrm{kg}$ of $F$. angulata extract for 14 days through gavage method (ischemia + F.A E $400 \mathrm{mg}$ / $\mathrm{kg})(10)$.

6.

Preparing the hydroalcoholic extract of Ferulago angulata In early May, F. angulata were collected from the Zagros mountain range in Khozestan province. The plant twigs were kept in a dark and dry environment for 2 weeks to dry them. After being dried and ground, they were placed in $72 \%$ ethanol and after three days of storage at room temperature we spread them out on a flat surface to dry out. After that, doses of 100, 200 and 400 of F. angulata extract were administered by normal saline and based on the prepared weight and through gavage for 14 days, every day at a certain hour (7-8 AM) (9).

Hypo-perfusion ischemia surgery procedure In this study, Schty method was used with slight modifications (10). In a way that after anesthetizing rats with ketamine/xylazine $(90 / 10 \mathrm{mg} / \mathrm{kg})$, and neck midline incision, carotid artery appeared and then was slowly separated from the vagus nerve and carotid artery was blocked within a week of each other.

Open field test

The open field test is used to evaluate stress and movement activities. The test was done by using a $72 \times 72 \mathrm{~cm}$ wooden field that was evenly divided into 16 homes $(18 \times 18 \mathrm{~cm})$ and had walls with a height of $36 \mathrm{~cm}$ that were white (11). A central house of $18 \times 18 \mathrm{~cm}$ was drawn in the middle of the open field. The rats were individually placed in the central square. In these circumstances, animals were passing from the central and outer lines and between the tests the considered environment was cleaned with cotton dipped in alcohol. For measuring the movement system time, the time duration of animals' mobility and immobility was recorded by the stopwatch during a specific time limit. The environmental conditions were the same for all groups and the test time was about 10 minutes and also in this test, the number of raised hands and the number of defecations were used to assess anxiety (11).

\section{Statistical methods}

Data were presented in the form of mean standard error of mean (mean + SEM) and one-way analysis of variance (ANOVA) was used followed by Tukey test. After obtaining information from different experimental groups, the results of the above groups were analyzed and $P<0.05$ was proposed as the indicator of significance. SPSS software was used for data analysis.

\section{Results}

Animal movement activity was evaluated by open field devices. The number of motor units in the open field test was significantly declined in ischemia group animals compared with the control group. Motor activity scores (number of passes in the marginal squares/number of passes in the central square) and the number of stools were recorded. In the assessment of anxiety, there was a significant difference between the control and ischemia group, reducing movement in the central square $(P<0.01)$, reduction in raising hands or rearing $(P<0.05)$, reducing movements in margin squares $(P<0.001)$ and increase in the number of defecation $(P<0.001)$, in ischemia group which shows that anxiety has increased in ischemia group compared to the control group. Administration of 100, 200 
and $400 \mathrm{mg} / \mathrm{kg}$ of $F$. angulata extract caused a reduction in raising hands/rearing especially in the dose of $200 \mathrm{mg} / \mathrm{kg}$ $(P<0.05)$ (Figure 1). Only the dose of $400 \mathrm{mg} / \mathrm{kg}$ of extract in ischemia rat was able to show a significant increase in the number of movements between the central houses in the open field (Figure 2) and the number of movements between the margin houses $(P<0.05)$ (Figure 3). Also a significant reduction was observed in the number of

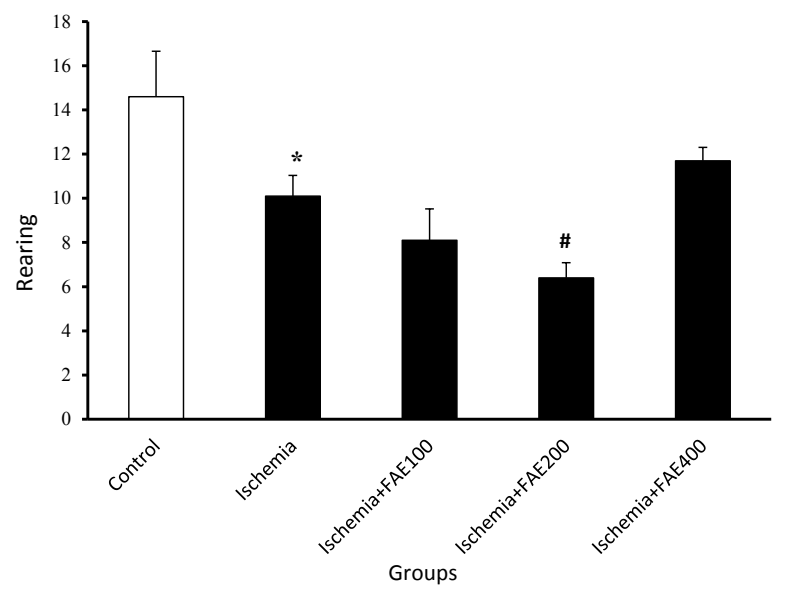

Figure 1. Comparison of the average anxiety (the number of raising hands/ Rearing) among the groups receiving different doses of Ferulago angulata extracts with ischemia and control group. The graph is plotted according to (mean $\pm \mathrm{SD}$ ). As can be seen, $F$. angulata extract caused a significant decrease in anxiety only at the dose of $200 \mathrm{mg} / \mathrm{kg}$. The sign of $\left(^{*}\right)$ indicates a significant difference with the control group and the sign of (\#) indicates a significant difference with the ischemia group (\#P<0.05, ${ }^{*} P<0.05, n=10$, one-way ANOVA and Tukey test).

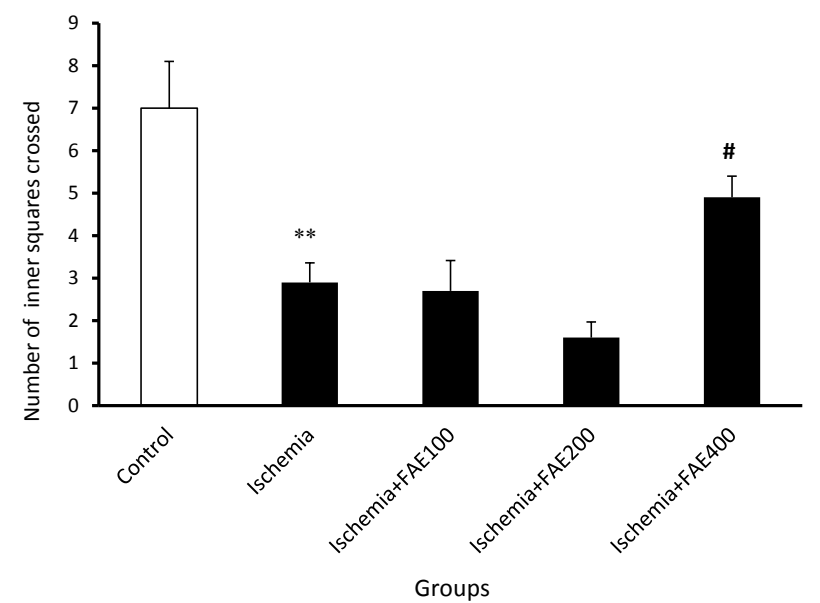

Figure 2. Comparison of the average movement activity (number of inner squares crossed in the open field) among the groups receiving different doses of the extract with ischemia and control group, the graph is plotted according to (mean $\pm \mathrm{SD}$ ), in this figure, Ferulago angulata extract at the dose of $400 \mathrm{mg} / \mathrm{kg}$ has led to a significant increase in the movement activities. The sign of $\left(^{* *}\right)$ indicates a significant difference with the control group and the sign of (\#) indicates a significant difference with the ischemia group (\#P<0.05, ${ }^{*} P<0.05, n=10$, one-way ANOVA and Tukey test). defecations in all 3 doses of $100(\mathrm{P}<0.01), 200$ and $400 \mathrm{mg} /$ kg $(P<0.001)$ (Figure 4$)$.

\section{Discussion}

According to the survey results, 14 days of oral prescription of $F$. angulata extract to the ischemic rats, improved anxiety and depression. Cerebral ischemia leads to neurological disorders such as mental and cognitive

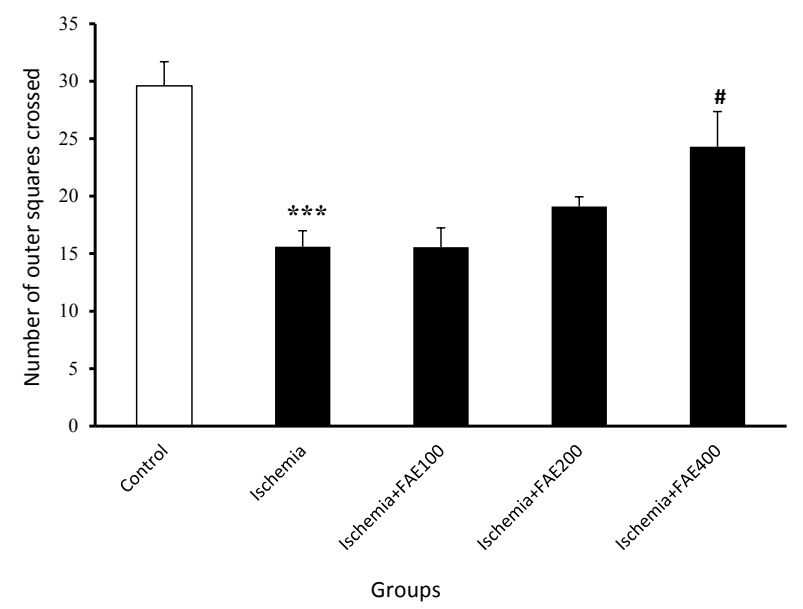

Figure 3. Comparison of the average movement activity (number of outer squares crossed in the open field) among the groups receiving different doses of the extract with ischemia and control group, the graph is plotted according to (mean $\pm \mathrm{SD}$ ), in this figure, Ferulago angulata extract at the dose of $400 \mathrm{mg} / \mathrm{kg}$ has led to a significant increase in the movement activities. The sign of $\left(^{*}\right)$ indicates a significant difference with the control group and the sign of (\#) indicates a significant difference with the ischemia group $\left(\# P<0.05,{ }^{*} P<0.05, \mathrm{n}=10\right.$, one-way ANOVA and Tukey test).

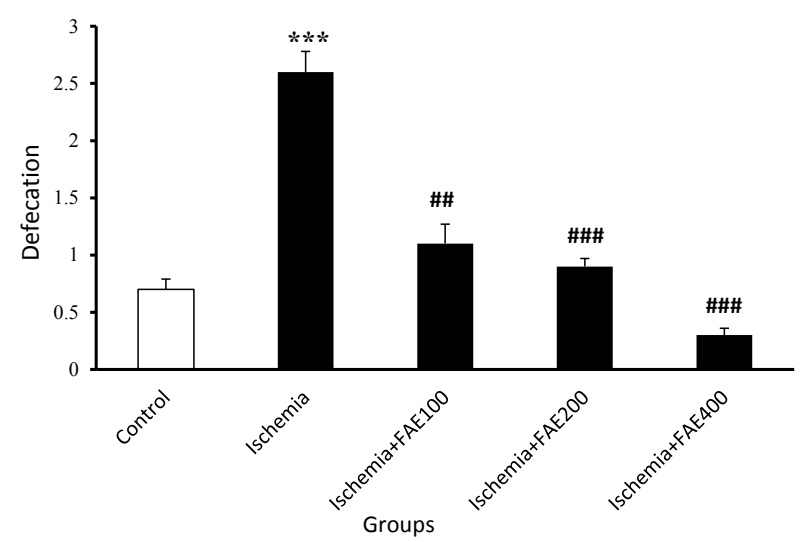

Figure 4. Comparison of the average number of defecation (anxiety) in the open field test among the groups receiving different doses of Ferulago angulata extract with ischemia and control group, the graph is plotted according to (mean \pm SD), as can be seen, $F$. angulata resulted in a significant decrease in the number of defecation at all three doses. The sign of $\left(^{*}\right)$ indicates a significant difference with the control group and the sign of (\#) indicates a significant difference with the ischemia group (\#\#\#P<0.001, \#\#P<0.01, ${ }^{* * *} P<0.001, \mathrm{n}=10$, one-way ANOVA and Tukey test). 
disorders, behavioral disorders including anxiety, mania and bipolar disorders (12). Oxidative stress, as a major cause of cerebral ischemic complication, leads to disorder in oxidant-antioxidant balance and potential damages (3). It has also a pivotal role in the pathogenesis of neurodegenerative and neurological diseases such as, Alzheimer's and Parkinson's diseases, as well as trauma and brain stroke (13). Several studies have shown that the production of free radicals will increase considerably after ischemia and Sesjo in 1984 suggested that there are many routes where free radicals are produced during ischemia such as proxy nitrite (13). Scientific evidence shows that free radicals have an undeniable role in the formation and extension of secondary brain lesions after brain stroke (14). Oxidative stress will arise due to the lack of balance among the formation of reactive oxygen species (ROS) and cellular antioxidant defense system and brain is very sensitive to oxidative stress. The expression of the genes of antioxidant enzymes (such as superoxide dismutase, glutathione peroxidase and glutathione reductase) are usually increased in the natural environment in response to the uncontrolled production of ROS (15). High levels of anxiety have been reported in rats with significant production of ROS in blood lymphocytes granulocytes and monocytes. These results confirm that there is a relationship between the levels of intracellular ROS in blood cells and anxiety-related behavior in rats. In addition, Yasunari et al presented a significant relationship between anxiety and ROS formation in individuals' monocytes (16). In recent researches, a close relationship has been observed between oxidative stress and anxiety both in human beings who suffer from anxiety disorders (intellectualpractical obsession disorder and panic disorder) and also in animals and humans that have shown high levels of anxiety (17). Phenolic compounds act as the electron donor and may neutralize unwanted reactions created by free radicals in the body (18). They also have various biological properties including antioxidant, anti-radical, anti-microbial and anti-inflammatory activities (19). For this reason, they are effective in stopping the process of nervous system destruction, prevention and treatment of many diseases including ischemia by inhibiting free radicals and protecting cells against oxidative reactions $(20,21)$. Therefore, considering the high prevalence of chronic and erosive diseases, plants should be used to provide antioxidants needed by the body especially plants that have high phenol and flavonoid compounds (19). According to many studies, it can be said that F. angulata extract with phenolic and antioxidant properties, it has the potential to be used as a natural antioxidant in the food and pharmaceutical industries $(22,23)$. It can be said that the extraction of $F$. angulata, having phenolic compounds and antioxidant properties, has the potential to be used in food and pharmaceutical industries as a natural antioxidant (6). In our previous studies, F. angulata was able to decline the oxidative stress factors in a quite significant way in both ischemia (24) and Parkinson (25) models.

\section{Conclusion}

Ferulago angulata extract reduces anxiety in animal models of ischemia, which is probably due to some phenolic compounds and its antioxidant activity. Probably, phenolic compounds of Ferulago angulata extract, through sweeping the free radicals produced by the procedure of brain ischemia, will lead to behavioral disorders recovery including the anxiety after ischemia.

\section{Acknowledgments}

The authors would like to thank the Research Deputy of Islamic Azad University, Izeh Branch, Gomishan Branch, Gorgan Center, who supported this research.

\section{Authors' contributions}

MRR: Design of the study and laboratory methods, preparation of PGSE and laboratory methods. ShAR: Preparation of the paper draft, statistical analysis and help in laboratory methods. Both authors read the final version of the article and confirmed its publication.

\section{Conflict of interests}

The authors declared no competing interests.

\section{Ethical considerations}

The experiments were confirmed by Ethical Committee in Vice Chancellor of Research of Islamic Azad University. (Ethical No: 1739608130014) Ethical issues (including plagiarism, misconduct, data fabrication, falsification, double publication or submission, redundancy) have been completely observed by the authors.

\section{Funding/Support}

Financial costs for this research was provided of an approved project at the Islamic Azad University Gomishan Branch, Gorgan Center (Grant No: 1739608130014).

\section{References}

1. Tsigos C, Chrousos GP. Hypothalamic-pituitary-adrenal axis, neuroendocrine factors and stress. J Psychosom Res. 2002;53(4):865-71.

2. Chan PH. Reactive oxygen radicals in signaling and damage in the ischemic brain. J Cereb Blood Flow Metab. 2001;21(1):2-14. doi: 10.1097/00004647-200101000-00002.

3. Tarawneh R, Galvin JE. Potential future neuroprotective therapies for neurodegenerative disorders and stroke. Clin Geriatr Med. 2010;26(1):125-47. doi: 10.1016/j. cger.2009.12.003.

4. Sabban EL, Kvetnansky R. Stress-triggered activation of gene expression in catecholaminergic systems: dynamics of transcriptional events. Trends Neurosci. 2001;24(2):91-8.

5. Sarkaki A, Farbood Y, Hashemi S, Rafiei Rad M. Pomegranate seed hydroalcoholic extract improves memory deficits in ovariectomized rats with permanent 
cerebral hypoperfusion/ischemia. Avicenna J Phytomed. 2015;5(1):43-55.

6. Hosseini N, Akbari M, Ghafarzadegan R, Shahmohammadi $\mathrm{R}$, Changizi-Ashtiyani S. Total phenol, antioxidant and antibacterial activity of the essential oil and extracts of Ferulago angulata ssp. Angulate. J Med Plants. 2012;11(43):80-9.

7. Demetzos C, Perdetzoglou D, Gazouli M, Tan K, Economakis C. Chemical analysis and antimicrobial studies on three species of Ferulago from Greece. Planta Med. 2000;66(6):560-3. doi: 10.1055/s-2000-8652.

8. Taran M, Ghasempour HR, Shirinpour E. Antimicrobial activity of essential oils of Ferulago angulata subsp. Jundishapur J Microbiol. 2010;3(2):10-4.

9. Mirzapour S, Rafieirad M, Rouhi L. Hydroalcoholic extract of Ferulago angulata Improves memory and pain in brain hypoperfusion ischemia in rats. Jundishapur J Nat Pharm Prod. 2015;10(1):e17451.

10. Sarkaki A, Rafieirad M, Farbood Y, Mansouri SFM. Cognitive deficiency induced by cerebral hypoperfusion/ ischemia improves by exercise and grape seed extract. Health Med J. 2012;6(4):1097-105.

11. Rafieirad M, Zangeneh Nezhad Z, Allahbakhshi E. Neuroprotective effects of oral ellagic acid on locomotor activity and anxiety-induced by ischemia/hypoperfusion in rat. Adv Environ Biol. 2014;8(1):83-8.

12. Acikgoz O, Gonenc S, Kayatekin BM, Uysal N, Pekcetin C, Semin I, et al. Methamphetamine causes lipid peroxidation and an increase in superoxide dismutase activity in the rat striatum. Brain Res. 1998;813(1):200-2.

13. Siesjo BK. Cell damage in the brain: a speculative synthesis. Acta Psychiatr Scand Suppl. 1984;313:57-91.

14. Heo JH, Han SW, Lee SK. Free radicals as triggers of brain edema formation after stroke. Free Radic Biol Med. 2005;39(1):51-70. doi: 10.1016/j. freeradbiomed.2005.03.035.

15. Hovatta I, Tennant RS, Helton R, Marr RA, Singer O, Redwine JM, et al. Glyoxalase 1 and glutathione reductase 1 regulate anxiety in mice. Nature. 2005;438(7068):662-6. doi: $10.1038 /$ nature 04250 .
16. Yasunari K, Watanabe T, Nakamura M. Reactive oxygen species formation by polymorphonuclear cells and mononuclear cells as a risk factor of cardiovascular diseases. Curr Pharm Biotechnol. 2006;7(2):73-80.

17. Bouayed J, Rammal H, Soulimani R. Oxidative stress and anxiety: relationship and cellular pathways. Oxid Med Cell Longev. 2009;2(2):63-7.

18. Manian R, Anusuya N, Siddhuraju P, Manian S. The antioxidant activity and free radical scavenging potential of two different solvent extracts of Camellia sinensis (L.) O. Kuntz, Ficus bengalensis L. and Ficus racemosa L. Food Chem. 2008;107(3):1000-7. doi: 1016/j. foodchem.2007.09.008.

19. Jamshidi M, Ahmadi Ashtiani HR, Rezazadeh SH, Fathi Azad F, Mazandarani M, Khaki A. Study on phenolicd and anioxidant activity of some selected plant of Mazandaran province. J Med Plants. 2010;9(34):177-83.

20. Gupta R, Singh M, Sharma A. Neuroprotective effect of antioxidants on ischaemia and reperfusion-induced cerebral injury. Pharmacol Res. 2003;48(2):209-15.

21. Helbecque N, Cottel D, Codron V, Berr C, Amouyel P. Paraoxonase 1 gene polymorphisms and dementia in humans. Neurosci Lett. 2004;358(1):41-4. doi: 10.1016/j. neulet.2003.12.100.

22. Khanahmadi M, Janfeshan K. Study on antioxidation property of Ferulago angulata plant. Asian J Plant Sci. 2006;5(3):521-6.

23. Ghasempour H, Shirinpour E, Heidari H. The Constituents of essential oils of Ferulago angulata (SCHLECHT) boiss at two different habitate, nevakoh and shahoo, zagross mountain, western IRAN. Iran J Sci Technology, Transaction. 2007;31:814-7.

24. Baser KH, Demirci B, Demirci F, Hashimoto T, Asakawa Y, Noma Y. Ferulagone: a new monoterpene ester from Ferulago thirkeana essential oil. Planta Med. 2002;68(6):5647. doi: $10.1055 / \mathrm{s}-2002-32557$.

25. Sharifi F, Rafieirad M, Sazegar H. Effects of Ferulago angulata extract against oxidative stress induced by 6-hydroxydopamine in rats. J Med Plants. 2015;1(53):3444. 